\title{
Deexcitation Characterization for Power Supply Protection in DC Shipboard Power Systems
}

S. Kim, D. Dujic, and S. Kim

This material is posted here with permission of the IEEE. Such permission of the IEEE does not in any way imply IEEE endorsement of any of EPFL's products or services. Internal or personal use of this material is permitted. However, permission to reprint / republish this material for advertising or promotional purposes or for creating new collective works for resale or redistribution must be obtained from the IEEE by writing to pubs-permissions@ieee. org. By choosing to view this document, you agree to all provisions of the copyright laws protecting it. 


\section{Deexcitation Characterization for Power Supply Protection in DC Shipboard Power Systems}

\author{
Seongil Kim, Drazen Dujic \\ Power Electronics Laboratory - PEL \\ École Polytechnique Fédérale de Lausanne - EPFL \\ Station 11, CH-1015 Lausanne, Switzerland \\ seongil.kim@epfl.ch,drazen.dujic@epfl.ch
}

\author{
Soo-Nam Kim \\ Future Power Grid Research Department \\ Hyundai Electric \& Energy Systems Co., Ltd. \\ Yongin, Republic of Korea \\ kimsoonam@hyundai-electric.com
}

\begin{abstract}
The deexcitation of a synchronous machine has been used for the protection of the power supply based on a diode rectifier in marine de power distribution networks. The fault current from the generator can be eliminated with the protection method utilizing the deexcitation. This allows for removing generator circuit breakers. In this method, the rectifier should be designed to manage the peak fault current and energy limited by the deexcitation. Hence, this paper presents the fault current characteristics with the generator deexcitation by analytical and experimental approaches. The fault behaviours under the deexcitation are theoretically described and the rectifier sizing is discussed for the peak fault current and the overloading capability of the diodes. The deexcitation characteristics are calculated by the analytical expression and investigated in a test setup for different subtransient reactance, fault resistance, exciter response, and time delay.
\end{abstract}

\section{INTRODUCTION}

According to [1], international shipping emitted more than $2.2 \%$ of the total $\mathrm{CO}_{2}$ emission in 2012. Furthermore, it is expected that the emission level will rise $50 \%$ to $250 \%$ by 2050 depending on future economic growth and energy consumption. As the global standard-setting authority, in 2011, the International Maritime Organization (IMO) adopted mandatory energy efficiency regulations [e.g., energy efficiency design index (EEDI) and energy efficiency management plan (SEEMP)] to control the greenhouse gas emissions from the shipping sector. With the new EEDI regulation, newly constructed ships of 400 gross tonnages and above have to increase the energy efficiency to comply with the reduction rates. Finally, the ships built in 2025 have to be $30 \%$ more efficient than the ships built in 2004.

Since 2013, as the prominent solution to meet the regulations, low-voltage dc (LVDC) networks have been applied to dynamic positioning and passenger vessels in commercial use (up to $20 \mathrm{MW}$ and around $1 \mathrm{kV}$, see Fig. 1) [2], [3]. Furthermore, there are lots of research activities on the dc shipboard power systems (SPS) to increase their power capability by employing medium-voltage dc technologies [4]-[8].

A protection scheme used for the commercial LVDC ships is based on a three-level protection [9]-[11] that is composed of three actions (see Fig. 2): first action - bus separation by solidstate bus-tie switches; second action - feeder protection by high-speed fuses; and third action - power supply protections
[12]. In this protection scheme, the bus-tie switch becomes $O F F$ to isolate the healthy bus from the faulty bus for a dc fault. Then, for the feeder fault in Fig. 1, the high-speed fuse installed at the faulty feeder disconnects the fault from the system. If the fuse does not work or the bus fault in Fig. 1 is generated, the fault current from the generator has to be blocked by the power supply protection, as the third action.

The power supply protection is strongly linked to the rectifier type. In case of a voltage source converter (VSC), an artificial short-circuit method is proposed in [13] and based on an intentionally-generated low-impedance path in the AC-side to block the fault current passing through the VSC. A foldback protection control is applied to the thyristor rectifier [10], [14]. On the other hand, with the protection method exploiting the deexcitation, the fault current from the generator to the diode rectifier can be eliminated without generator circuit breakers [11], [13].

Although the deexcitation of the generator is activated, the generator produces a very high amplitude of current during the first few cycles. After that, due to the decrease in the excitation current, the fault current is gradually reduced, and finally, it becomes zero. Hence, the diodes in the rectifier should be

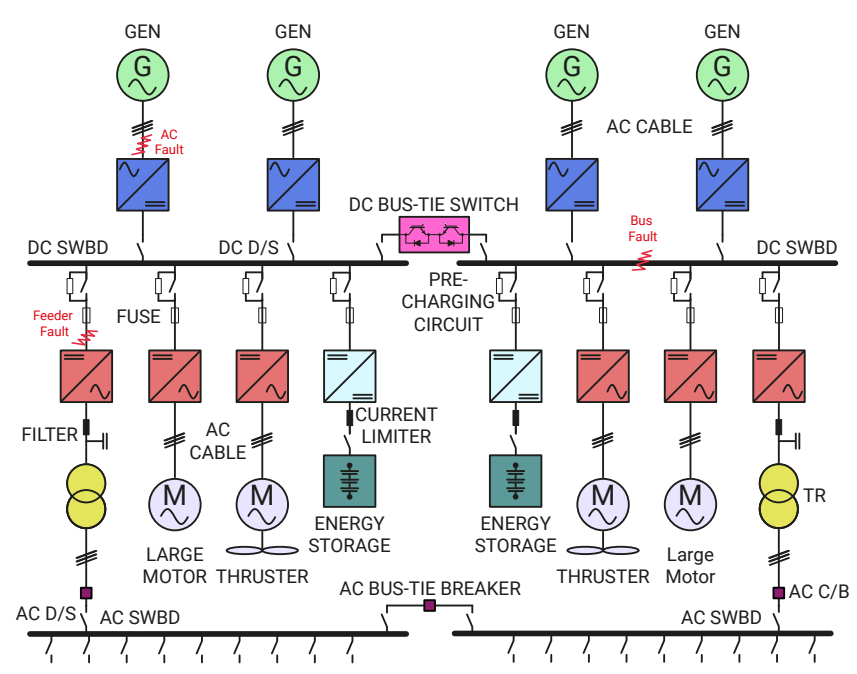

Fig. 1: Schematic diagram of two-dc bus SPS. 


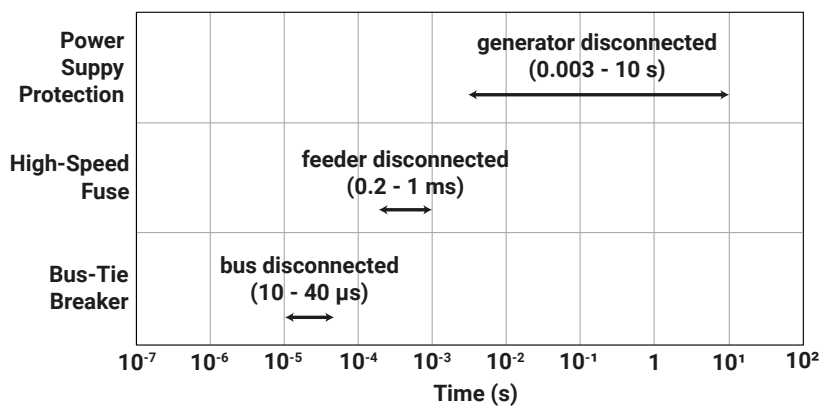

Fig. 2: Operating time frames of the three actions in the threelevel protection [9]. Selective operation is provided by their different operating ranges and the time margins.

sized with the consideration of those dynamic characteristics of the synchronous generator and the excitation systems under the worst condition. This is because of no ac breaker between the generator and the rectifier as well as no dc breaker between the rectifier and the main bus (see Fig. 1).

This paper presents the fault current characteristics with the generator deexcitation by analytical and experimental approaches. In Section II, the fault behaviours under the deexcitation are theoretically described and the rectifier sizing is discussed for the peak fault current and the overloading capability of the diodes. Section III presents the deexcitation characteristics investigated by the analytical and experimental approaches for different subtransient reactance, fault resistance, exciter response, and time delay. The findings and the main results are summarized in Section IV.

\section{ThEORETICAL CONSIDERATIONS}

For a six-pulse diode rectifier that is currently employed for LVDC SPSs, the dc short-circuit current with the generator deexcitation is analyzed with its analytical description introduced in [12]. After that, the design consideration of the diode rectifier is also discussed for two important factors: peak non-repetitive surge current and limiting load integral.

\section{A. Analytical Expression}

The flow of a dc short-circuit current is same as that of the load current in the six-pulse diode rectifier. The dc fault current conducts one diode in the positive rail $\left(D_{1}, D_{3}\right.$, and $\left.D_{5}\right)$ to one diode in the negative rail $\left(D_{2}, D_{4}\right.$, and $\left.D_{6}\right)$, as illustrated in Fig. 3a. Each diode conducts for every $120^{\circ}$ cycle. Thus, it could be stated that the dc short-circuit is the continuous line-to-line faults with the interval angle of $120^{\circ}$. Moreover, the continuous faults can also make the circuit balanced over several cycles, while the circuit is not balanced at the instant of every conduction. From that, the circuit under the dc shortcircuit is equivalent to a simple RL circuit connected across the line-to-line voltage [see Fig. 3b].

The fault current provided by the synchronous generator consists of three distinct periods: subtransient period, lasting from one to three cycles; transient period, sustaining longer cycles; and finally, steady-state period, remaining constant

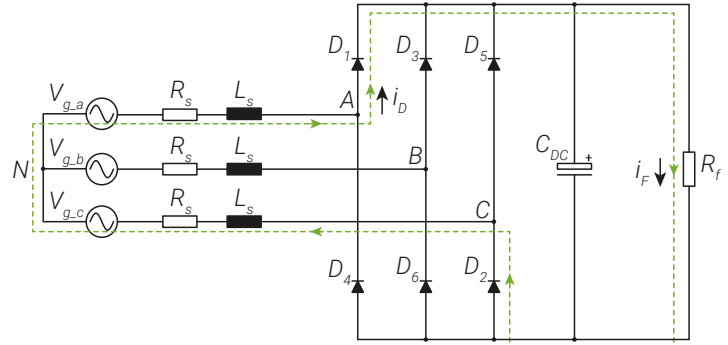

(a)

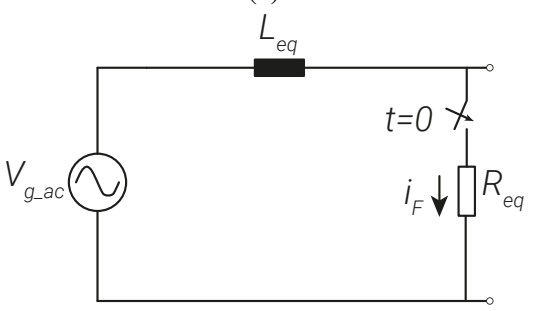

(b)

Fig. 3: DC short-circuit of six-pulse diode rectifier with ideal three-phase source: (a) diagram of current flow from the positive rail to the negative rail and (b) equivalent circuit (RL expression).

current (see Fig. 4). These dynamics in the generator are due to the change of the direct axis machine parameters depending on the period: subtransient reactance $\left(X_{d}^{\prime \prime}\right)$ and time constant $\left(T_{d}^{\prime \prime}\right)$, transient reactance $\left(X_{d}^{\prime}\right)$ and time constant $\left(T_{d}^{\prime}\right)$, and steady-state reactance $\left(X_{d}\right)$. In addition, the dc component decays with a time constant $\left(T_{a}\right)$ which is equal to the average of direct-axis and quadrant-axis subtransient reactance $\left(X_{d}^{\prime \prime}\right.$

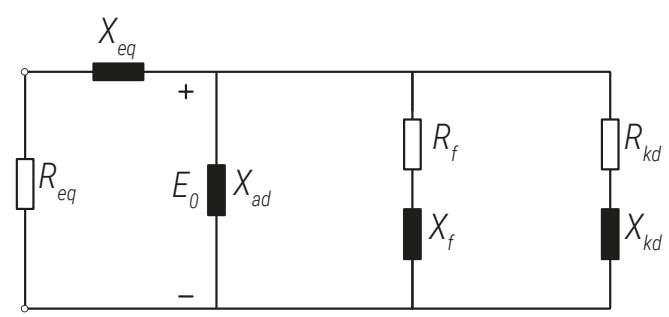

(a)

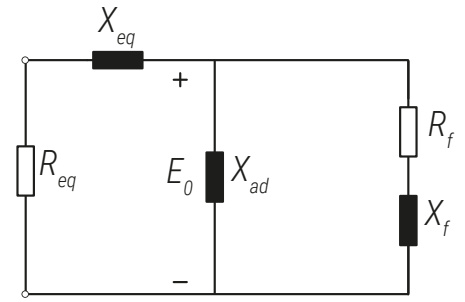

(b)

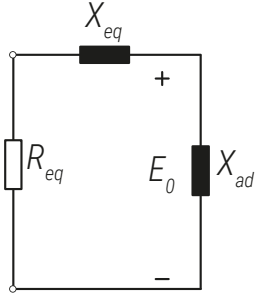

(c)
Fig. 4: Equivalent circuit models of synchronous machine during fault condition: (a) subtransient period, (b) transient period, and (c) steady-state period. 


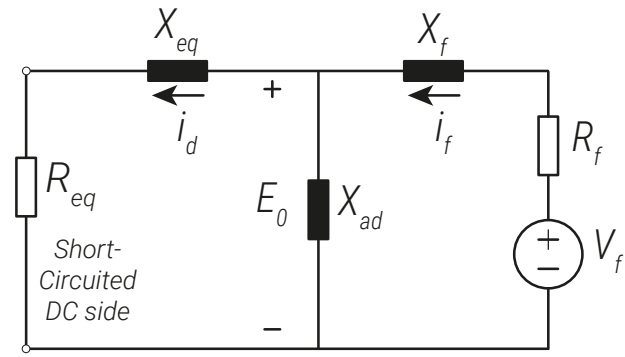

Fig. 5: Equivalent circuit model with short-circuited stator and field voltage.

and $X_{q}^{\prime \prime}$ ).

Once the deexcitation is activated, the field voltage varies from the initial value $\left(V_{f}\right)$ to zero with the exciter time constant $\left(T_{e}\right)$ and the field time constant (the transient time constant, $X_{d}^{\prime}$ ). Furthermore, this field suppression makes the internal generator voltage $\left(E_{0}\right)$ to zero with the deexcitation response $[F(t)]$ which is composed of both the time constants as

$$
\begin{aligned}
F(t)=u( & \left.-t+t_{d}\right) \\
& +u\left(t-t_{d}\right) \frac{T_{d}^{\prime} e^{-\left(t-t_{d}\right) / T_{d}^{\prime}}-T_{e} e^{-\left(t-t_{d}\right) / T_{e}}}{T_{d}^{\prime}-T_{e}}
\end{aligned}
$$

where $t_{d}$ is the time delay to activate the deexcitation after the fault instant.

As above described, by the consideration of the equivalent circuit diagram, the generator dynamics, and the deexcitation response, the current through the diode is [12]

$$
\begin{aligned}
& i_{D}(t)=\sqrt{2} E_{0} Y(t) F(t) \sin (\omega t+\alpha-\phi) \\
& +\frac{\sqrt{2} E_{0}}{\sqrt{R_{e q}{ }^{2}+X_{d}^{\prime \prime 2}}} \sin (\alpha-\phi) e^{-\frac{t}{T_{a}}}
\end{aligned}
$$

where

$$
\begin{aligned}
E_{0}= & V_{g_{-} a c}=V_{g_{\_} a}-V_{g_{-} c}, \\
Y(t)= & \left(\frac{1}{\sqrt{R_{e q}^{2}+X_{d}^{\prime 2}}}-\frac{1}{\sqrt{R_{e q}^{2}+X_{d}^{\prime 2}}}\right) e^{-\frac{t}{T_{d}^{\prime \prime}}} \\
& +\left(\frac{1}{\sqrt{R_{e q}^{2}+X_{d}^{\prime 2}}}-\frac{1}{\sqrt{R_{e q}^{2}+X_{d}^{2}}}\right) e^{-\frac{t}{T_{d}^{\prime}}} \\
& +\frac{1}{\sqrt{R_{e q}^{2}+X_{d}^{2}}}, \\
T_{a}= & \frac{X_{d}^{\prime \prime}+X_{q}^{\prime \prime}}{2 \omega R_{e q}},
\end{aligned}
$$

and the parameters of $Y(t)$ are provided in the Appendix. As shown in Fig. 3a, the fault current conducting through the diodes is rectified by the converter. Therefore, it is possible to neglect the sinusoidal term in (2) and the dc fault current $\left(i_{F}\right)$ is finally [12]

$$
i_{F}(t)=\sqrt{2} E_{0}\left(Y(t) F(t)+\frac{\sin (\alpha-\phi)}{\sqrt{R_{e q}^{2}+X_{d}^{\prime \prime 2}}} e^{-\frac{t}{T_{a}}}\right)
$$

\section{B. Rectifier Sizing}

While the dc fault current in (3) does not include the sinusoidal term in (2), the maximum peak current in both equations are the same when $\alpha-\phi=\pi / 2$ and $t=0$. With these conditions, it is possible to select the rating of the peak non-repetitive surge current $\left(I_{F S M}\right)$ as

$$
\begin{aligned}
I_{F S M} \geq i_{\text {Dpeak }} & =i_{\text {Fpeak }} \\
& =\frac{\sqrt{2} E_{0}}{\sqrt{R_{e q}{ }^{2}+X_{d}^{\prime \prime 2}}}\left(1+\frac{X_{d}^{\prime \prime}}{\sqrt{R_{e q}{ }^{2}+X_{d}^{\prime \prime 2}}}\right)
\end{aligned}
$$

The fault resistance cannot be determined and thus the rectifier has to be sized under the worst condition. In (4), the worst conditions is $R_{e q}=0$ and the peak non-repetitive surge current of the diode has to be higher than $i_{\text {Fpeak-max }}=2 \sqrt{2} E_{0} / X_{d}^{\prime \prime}$.

Aforementioned, the six-pulse rectifier conducts the fault current for every $120^{\circ}$ cycle. Therefore, each diode only suffers one-third of the energy of the dc fault curent $\left(i_{F}{ }^{2} t_{F}\right)$. Moreover, the activation time of the deexcitation (called time delay, $2.5 \mathrm{~ms}$ in [11]) may increase the fault energy. Hence, the diode has to be sized to sustain the maximum fault energy passing through the diode under the condition of $\phi=\pi / 2$ and the time delay as

$$
\begin{aligned}
I^{2} t_{D} & \geq \frac{1}{3} \int_{0}^{\infty} i_{F}^{2}(t) d t \\
& \geq \frac{2}{3} E_{0}^{2} \int_{0}^{\infty}\left\{Y(t) F(t)+\frac{1}{\sqrt{R_{e q}^{2}+X_{d}^{\prime \prime 2}}} e^{-\frac{t}{T_{a}}}\right\}^{2} d t
\end{aligned}
$$

If the fault energy stresses are below the limiting load integral of the diode provided in the datasheets, the diodes can be recovered to be a normal state after the fault event. It states that the diode can sustain a large number of fault events if they are properly cooled down after the heating up by the faults.

\section{DeEXCITATION Characteristics}

Analytical calculations and experimental tests are conducted to characterize the dc short-circuit current under the deexcitation measure. In this study, the following system factors are taken into account: subtransient reactance $\left(X_{d}^{\prime \prime}\right)$, fault resistance $\left(R_{f}\right)$, exciter response $\left(T_{e}\right)$, and time delay $\left(t_{d}\right)$. 


\section{A. Study Parameters and Test Setup}

The parameters for analytical studies are provided in Table I. With these parameters, the calculation of dc short-circuit currents and energies are performed for different system factors.

Furthermore, the deexcitation tests with the test setup rated for $10 \mathrm{~kW}$ and $500 \mathrm{Vdc}$, as presented in Fig. 6, are carried out under the short-circuited dc side with fault resistance. The test setup is composed of a dc motor drive, a synchronous generator with one-quadrant automatic voltage regulator, a six-

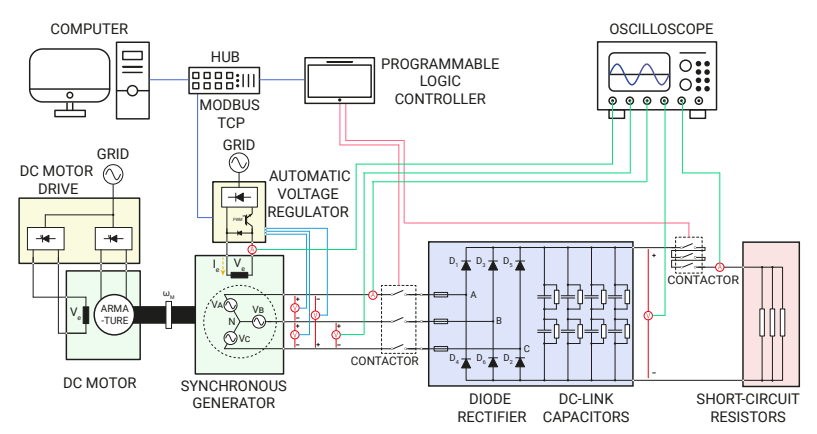

(a)

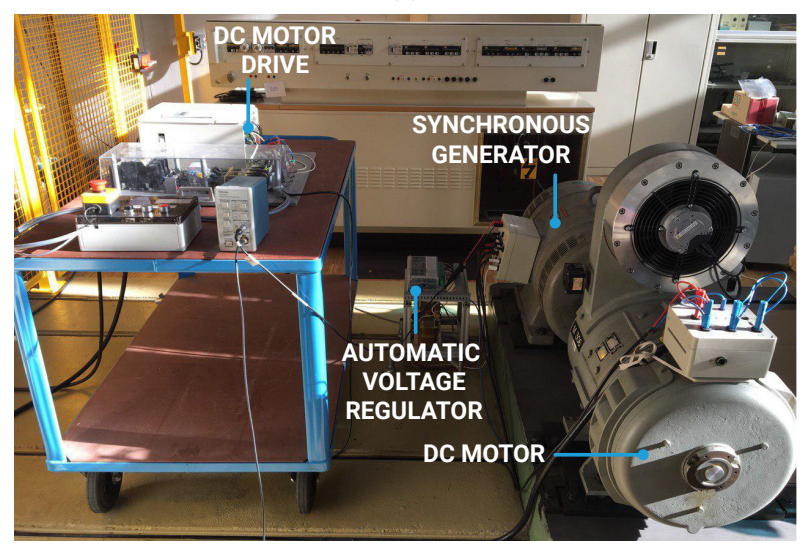

(b)

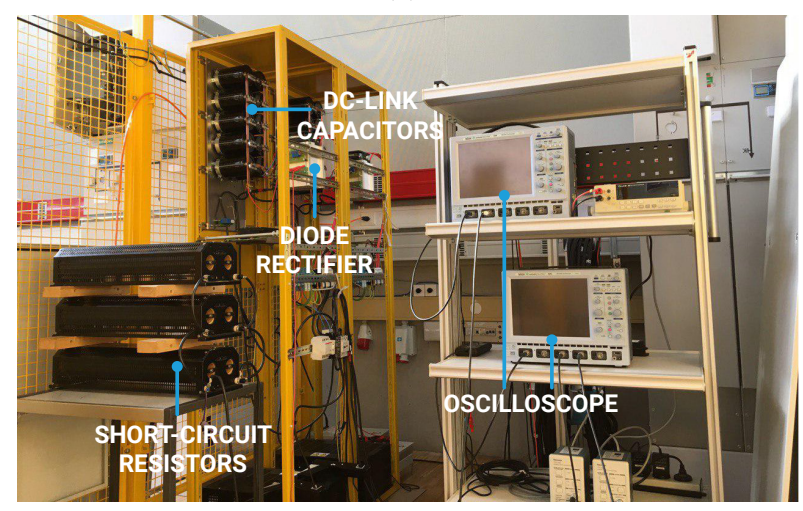

(c)

Fig. 6: Experimental setup: (a) schematic diagram, (b) physical implementation-generator side, and (c) physical implementation-rectifier and load side.
TABLE I: Synchronous generator parameters used for the calculation of dc short-circuit current [15].

\begin{tabular}{cc}
\hline \hline Parameters & Values \\
\hline$E_{0}$ & $1 \mathrm{pu}$ \\
$\omega$ & $377 \mathrm{rad} / \mathrm{s}$ \\
$T_{d}^{\prime \prime} ; T_{d}^{\prime} ;$ and $T_{a}$ & $0.03 \mathrm{~s} ; 1.5 \mathrm{~s} ;$ and $0.15 \mathrm{~s}$ \\
$X_{d}^{\prime \prime} ; X_{d}^{\prime} ; X_{d} ;$ and $X_{q}^{\prime \prime}$ & $0.22 \mathrm{pu} ; 0.28 \mathrm{pu} ; 1.0 \mathrm{pu} ;$ and $0.29 \mathrm{pu}$ \\
\hline \hline
\end{tabular}

pulse diode rectifier with dc-link capacitors, and short-circuit fault resistors. The synchronous generator, available in the laboratory, does not include damping winding (no subtransient dynamics) and is equipped with the direct excitation.

The fault resistance in the setup is manipulated by either series or parallel combination of the three resistors in Fig. 6c. Different exciter time constants $\left(T_{e}\right)$ and time delays $\left(t_{d}\right)$ are generated by a programmable logic controller.

\section{B. Influence of Subtransient Reactance}

In [11], a synchronous generator, specially designed to have high subtransient reactance $\left(X_{d}^{\prime \prime}\right)$, is used to reduce the initial dc fault current. However, the effect of the subtransient reactance is not discussed concerning the fault energy in [11]. For this reason, the dc fault current and its energy by (3) are calculated for three subtransient reactance values: $0.22 \mathrm{pu}$, $0.11 \mathrm{pu}$, and $0.33 \mathrm{pu}$. Note that the experimental tests for the subtransient reactance are not conducted due to no damper winding in the machine.

The calculation results show that the initial dc fault current can be minimized by employing the generator having a high value of the subtransient reactance. When the fault current reaches the transient period, there are no differences in the amplitude of the current. With this behaviour, the fault energy gaps among the three cases become larger during the subtransient period and then the gaps are maintained for the other periods. By the consideration of short subtransient time constant $\left(T_{d}^{\prime \prime}\right)$, it can be stated that the high subtransient reactance is effective to protect the diode from the peak short-

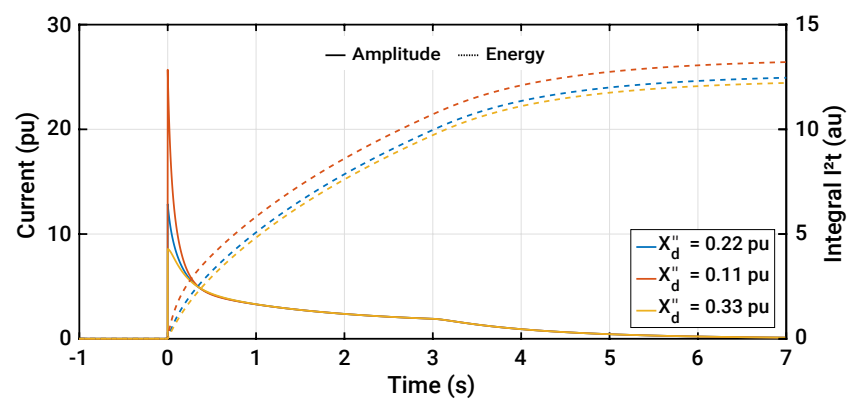

Fig. 7: Influence of subtransient reactance. Note that the analytical calculations are only provided due to the limitation of the physical machine. 


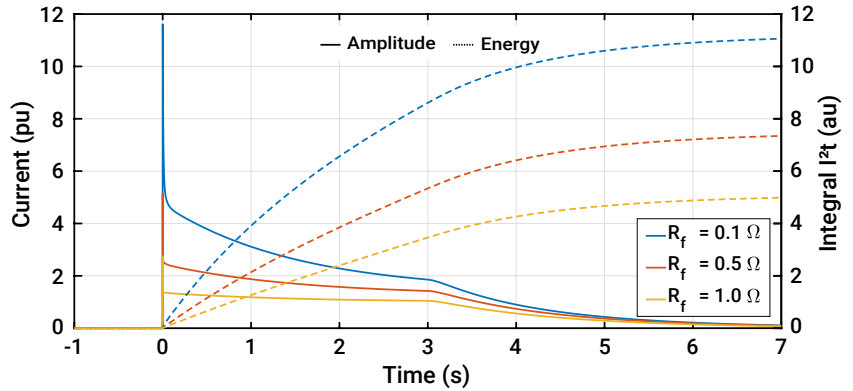

(a)

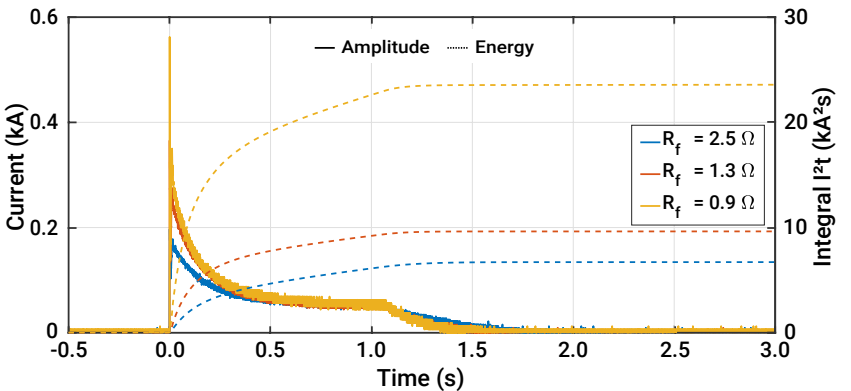

(b)

Fig. 8: Influence of fault resistance: (a) analytical calculations and (b) experimental tests.

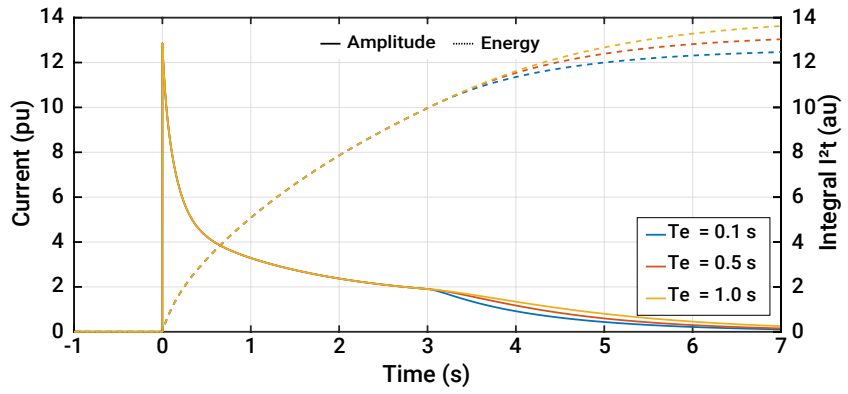

(a)

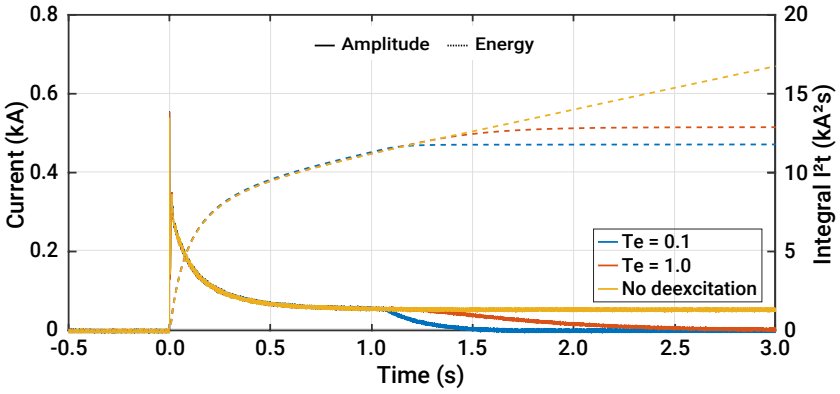

(b)

Fig. 9: Influence of exciter response: (a) analytical calculations and (b) experimental tests.

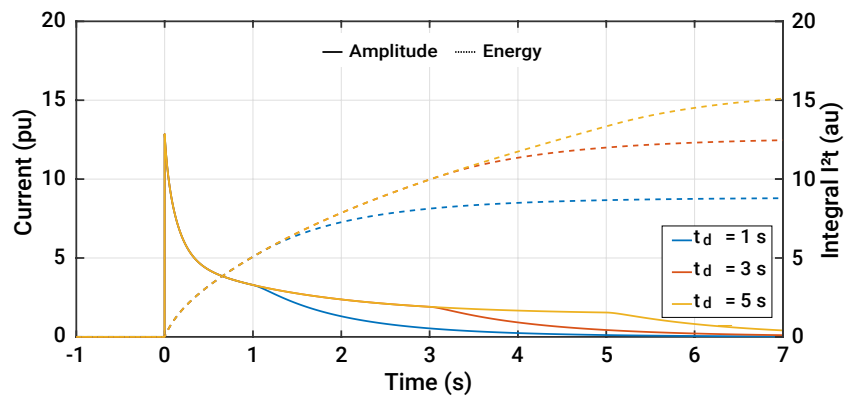

(a)

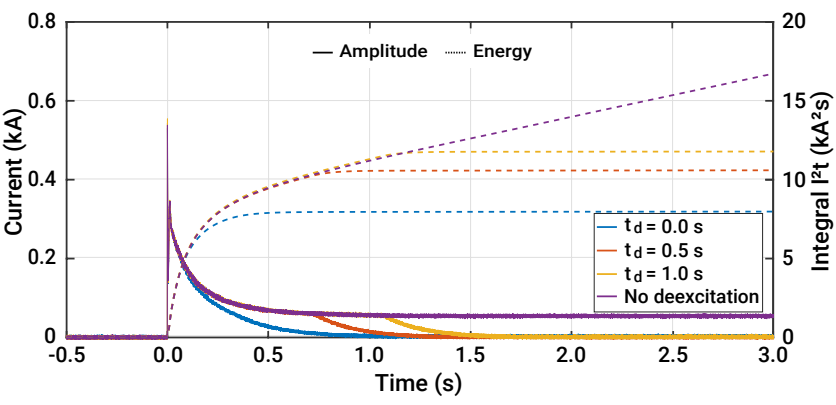

(b)

Fig. 10: Influence of time delay: (a) analytical calculations and (b) experimental tests.

circuit current, while its contribution for the diode protection is not high in terms of the limiting load integral $\left(I^{2} t_{D}\right)$.

\section{Influence of Fault Resistance}

While the bolted dc short-circuit occurs in the system, the fault resistance cannot be zero. The fault comes with certain fault resistance that is a function of the arc phenomena [16]. This implies that the dc fault may occur with different fault resistances. To analyse the influence of fault resistances, the dc short-circuit currents are analytically calculated and tested for different fault resistance: analytical approach - $0.1 \Omega, 0.5 \Omega$, and $1.0 \Omega$ and experimental approach $-0.9 \Omega, 1.3 \Omega$, and $2.5 \Omega$.

As shown in Fig. 8a, the fault resistance gives the impacts on the fault current for the whole period. Besides, low fault resistance shows very high initial fault current due to the high steady-state component as well as the high dc component, as described in (3). This trend is also observed in Fig. 8b. Low fault resistance develops high dc fault current, as expected.

\section{Influence of Exciter Type}

The deexcitation characteristics depends on the exciter type, e.g., brushless excitation systems have a higher time constant (or slow response) compared with direct excitation systems. The influence of the exciter response is analyzed with different exciter time constant in the study: analytical approach $-0.1 \mathrm{~s}$, $0.5 \mathrm{~s}$, and $1.0 \mathrm{~s}$ and experimental approach $-0.1 \mathrm{~s}, 1.0 \mathrm{~s}$, and no deexcitation.

When the deexcitation is activated at $3 \mathrm{~s}$ in Fig. 9a and at $1 \mathrm{~s}$ in Fig. 9b, rise of the rate of fault energy decreases with its time constant. Fig. 9 shows that lower time constant allows 
aiding to reduce the fault energy. In other word, the rectifier fed by the generator based on the brushless excitation systems should have higher limiting load integral than that based on the direct excitation systems.

\section{E. Influence of Time Delay}

As earlier mentioned, the deexcitation cannot immediately be activated after the fault. There are certain time delays for fault detection, fault localization, postprocessing, protection coordination, and so on. This time delay connected with the deexcitation activation is examined for different time delay: analytical approach $-1 \mathrm{~s}, 3 \mathrm{~s}$, and $5 \mathrm{~s}$ and experimental approach - $0 \mathrm{~s}, 0.5 \mathrm{~s}, 1.0 \mathrm{~s}$, and no deexcitation.

The study results (see Fig. 10) demonstrate that the time delay plays a role to boost the fault energy. In other words, the fast activation of the deexcitation can mitigate the fault energy and the time delay cannot be ignored for rectifier design and protection.

\section{Conclusion}

This paper has presented the study results on the dc fault characteristics under the deexcitation for the synchronous generator-diode rectifier. The diode rectifier sizing is also discussed for the peak fault current and the overloading capability of the diodes. The analytical calculations and the experimental tests are conducted for different subtransient reactance, fault resistance, exciter response, and time delay.

The analysis results provide important information: high subtransient reactance is effective to reduce the initial dc fault current, but the effect of the fault energy mitigation is not high due to the short subtransient period; low fault resistance develops high dc fault current, while the resistance is not controllable in practice; and faster exciter response and less time delay allow aiding to mitigate the fault energy. Furthermore, the system factors studied in this paper should be considered for rectifier sizing and protection coordination.

\section{APPENDIX}

The parameters for $Y(t)$ in (2) are

$$
\begin{aligned}
X_{d} & =X_{e q}+X_{a d}, \\
X_{d}^{\prime} & =X_{e q}+\left(\frac{1}{X_{a d}}+\frac{1}{X_{f}}\right)^{-1}, \\
X_{d}^{\prime \prime} & =X_{e q}+\left(\frac{1}{X_{a d}}+\frac{1}{X_{f}}+\frac{1}{X_{k d}}\right)^{-1}, \\
T_{d}^{\prime} & =\frac{1}{\omega R_{F}}\left(X_{F}+\left(\frac{1}{X_{e q}}+\frac{1}{X_{a d}}\right)^{-1}\right), \text { and } \\
T_{d}^{\prime \prime} & =\frac{1}{\omega R_{k d}}\left(X_{k d}+\left(\frac{1}{X_{e q}}+\frac{1}{X_{a d}}+\frac{1}{X_{f}}\right)^{-1}\right) .
\end{aligned}
$$

\section{ACKNOWLEDGMENT}

This work was supported by Hyundai Electric and Energy Systems Co, Ltd., Republic of Korea.

\section{REFERENCES}

[1] “Third IMO Greenhouse Gas Study 2014,” IMO report, pp. 1-295, 2015.

[2] "Innovative diesel-electric propulsion systems," Available: https://new.siemens.com/global/en/markets/marine/electric-propulsionand-drives.html [Accessed: Dec. 16, 2019].

[3] "Ring network for multi-megawatt DC power system," The Switch, 2020.

[4] U. Javaid, F. D. Freijedo, D. Dujic, and W. van der Merwe, "Dynamic Assessment of Source-Load Interactions in Marine MVDC Distribution," IEEE Transactions on Industrial Electronics, vol. 64, no. 6, pp. 4372-4381, Jun. 2017.

[5] K. Satpathi, V. M. Balijepalli, and A. Ukil, "Modeling and real-time scheduling of dc platform supply vessel for fuel efficient operation," IEEE Transactions on Transportation Electrification, vol. 3, no. 3, pp. 762-778, Sep. 2017.

[6] J. J. Valera-Garcia and I. Atutxa-Lekue, "On the optimal design of hybrid-electric power systems for offshore vessels," IEEE Transactions on Transportation Electrification, vol. 5, no. 1, pp. 324-334, Mar. 2019.

[7] R. M. Cuzner and V. Singh, "Future shipboard mvde system protection requirements and solid-state protective device topological tradeoffs," IEEE Journal of Emerging and Selected Topics in Power Electronics, vol. 5, no. 1, pp. 244-259, Mar. 2017.

[8] W. Li, A. Monti, and F. Ponci, "Fault detection and classification in medium voltage dc shipboard power systems with wavelets and artificial neural networks," IEEE Transactions on Instrumentation and Measurement, vol. 63, no. 11, pp. 2651-2665, Nov. 2014.

[9] S. Kim, S.-N. Kim, and D. Dujic, "Extending protection selectivity in dc shipboard power systems by means of additional bus capacitance," IEEE Transactions on Industrial Electronics, vol. 67, no. 5, pp. 3673-3683, May. 2020.

[10] J. F. Hansen, J. O. Lindtjørn, and K. Vanska, "Onboard DC Grid for enhanced DP operation in ships," in Dynamic Positioning Conference, Houston, 2011.

[11] S. O. Settemsdal, "Enhanced safety in power plant solutions proven by testing," ECPE Workshop, DC Grids, Technologies and Applications, Apr. 2018.

[12] S. Kim, S.-N. Kim, and D. Dujic, "Impact of synchronous generator deexcitation dynamics on the protection in marine dc power distribution networks," IEEE Transactions on Transportation Electrification, pp. 1$1,2020$.

[13] S. Kim, D. Dujic, and S. Kim, "Protection schemes in low-voltage DC shipboard power systems," in PCIM Europe 2018; International Exhibition and Conference for Power Electronics, Intelligent Motion, Renewable Energy and Energy Management, pp. 1-7, Jun. 2018.

[14] D. Dong, Y. Pan, R. Lai, X. Wu, and K. Weeber, "Active fault-current foldback control in thyristor rectifier for dc shipboard electrical system," IEEE Journal of Emerging and Selected Topics in Power Electronics, vol. 5, no. 1, pp. 203-212, Mar. 2017.

[15] "Ieee guide for synchronous generator modeling practices and applications in power system stability analyses," IEEE Std 1110-2002 (Revision of IEEE Std 1110-1991), pp. 1-80, Nov. 2003.

[16] J. C. Das, "Arc flash hazard calculations in lv and mv dc systems part 2: Analysis," IEEE Transactions on Industry Applications, vol. 50, no. 3, pp. 1698-1705, May. 2014. 